\title{
Measurements with Pinhole and Coded Aperture Gamma-Ray Imaging Systems
}

\section{January 2010}

Prepared by

N. M. Abdul-Jabbar

University of California, Berkley
A. A. Solodov, J. P. Hayward, K. P. Ziock, and A. C. Raffo-Caiado Oak Ridge National Laboratory

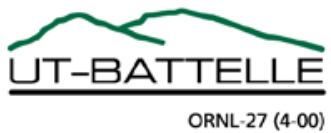




\section{DOCUMENT AVAILABILITY}

Reports produced after January 1, 1996, are generally available free via the U.S. Department of Energy (DOE) Information Bridge.

Web site http://www.osti.gov/bridge

Reports produced before January 1, 1996, may be purchased by members of the public from the following source.

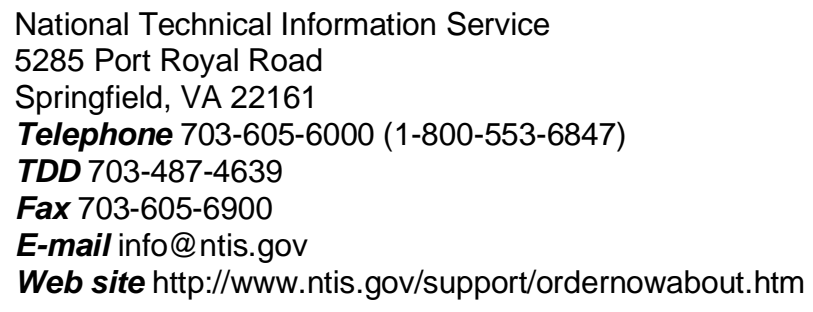

Reports are available to DOE employees, DOE contractors, Energy Technology Data Exchange (ETDE) representatives, and International Nuclear Information System (INIS) representatives from the following source.

Office of Scientific and Technical Information

P.O. Box 62

Oak Ridge, TN 37831

Telephone 865-576-8401

Fax 865-576-5728

E-mail reports@osti.gov

Web site http://www.osti.gov/contact.html

This report was prepared as an account of work sponsored by an agency of the United States Government. Neither the United States Government nor any agency thereof, nor any of their employees, makes any warranty, express or implied, or assumes any legal liability or responsibility for the accuracy, completeness, or usefulness of any information, apparatus, product, or process disclosed, or represents that its use would not infringe privately owned rights. Reference herein to any specific commercial product, process, or service by trade name, trademark, manufacturer, or otherwise, does not necessarily constitute or imply its endorsement, recommendation, or favoring by the United States Government or any agency thereof. The views and opinions of authors expressed herein do not necessarily state or reflect those of the United States Government or any agency thereof. 


\title{
MEASUREMENTS WITH PINHOLE AND CODED APERTURE GAMMA-RAY IMAGING SYSTEMS
}

\author{
N.M. Abdul-Jabbar \\ University of California, Berkley

\begin{abstract}
A. A. Solodov, J. P. Hayward, K. P. Ziock, and A. C. Raffo-Caiado Oak Ridge National Laboratory
\end{abstract}

Date Published: January 2010

Prepared by OAK RIDGE NATIONAL LABORATORY

Oak Ridge, Tennessee 37831-6283

managed by

UT-BATTELLE, LLC

for the

U.S. DEPARTMENT OF ENERGY

under contract DE-AC05-00OR22725 



\section{CONTENTS}

\section{Page}

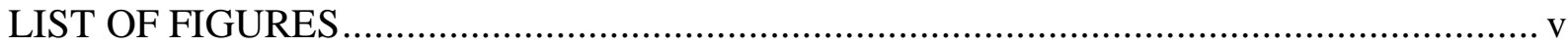

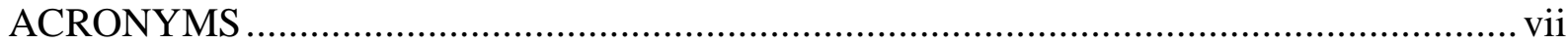

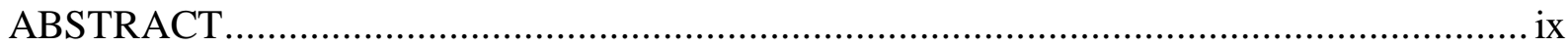

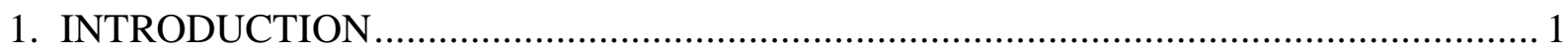

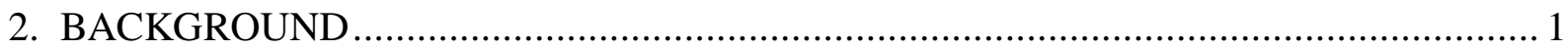

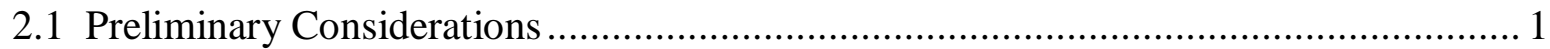

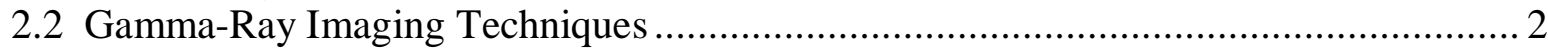

2.2.1 Compton Imaging ............................................................................... 2

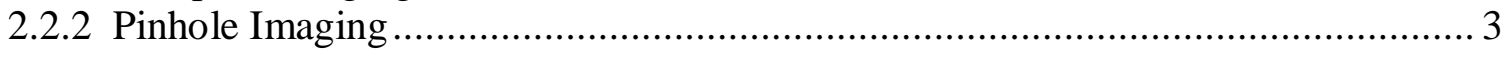

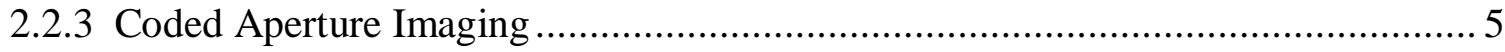

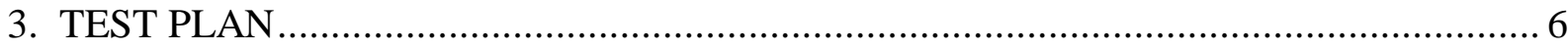

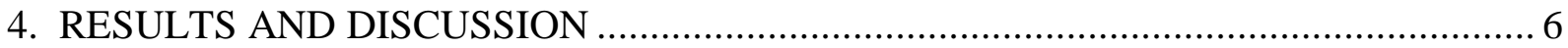

4.1 Preliminary Test .......................................................................................... 6

4.2 Further Tests with Coded Aperture Imager ................................................... 7

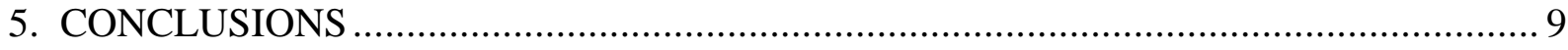

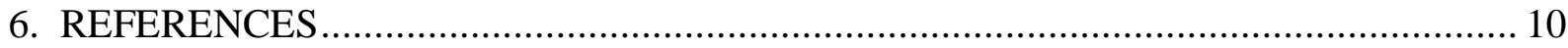





\section{LIST OF FIGURES}

Figure

Page

1 Portable 3D-DIV system. .............................................................................. 2

2 Compton image back-projected onto a 3D-DIV map ............................................ 3

3 A conic imaging element derived from an interaction sequence of two energy depositions $\left(E_{1}, E_{2}\right)$ at $\mathrm{p} 1$ and $\mathrm{p} 2$ from an incident gamma-ray source with energy $E_{\gamma} \ldots . .3$

$4 \quad$ Schematic showing the mechanism of pinhole imaging ...................................... 4

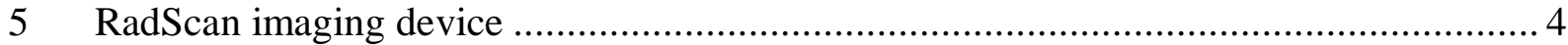

6 Images produced with coded apertures arise out of source pixels from a source field casting unique shadows onto the detector ........................................................ 5

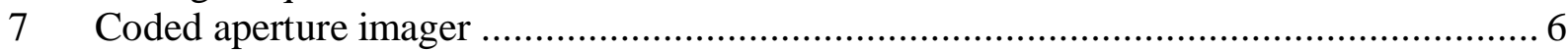

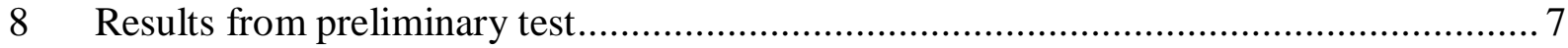

$9 \quad$ Experimental setup and results from first mock-up .......................................... 7

10 HEPA filter test setup and radiometric image after $3 \mathrm{~h}$ integration.............................. 8

11 Image obtained from a setup with three 30.48 by $60.96 \mathrm{~cm}^{2} \mathrm{U}_{3} \mathrm{O}_{8}$ card sources............ 8

12 Flow loop setup and radiometric image after $16 \mathrm{~h}$ integration ................................. 9 



\section{ACRONYMS}

$\begin{array}{ll}\text { 2D } & \text { two-dimensional } \\ \text { 3D } & \text { three-dimensional } \\ \text { 3D-DIV } & \text { three-dimensional design information verification } \\ \text { HEPA } & \text { high-efficiency particulate air } \\ \text { JRC } & \text { Joint Research Centre } \\ \text { LLNL } & \text { Lawrence Livermore National Laboratory } \\ \text { ORNL } & \text { Oak Ridge National Laboratory } \\ U_{3} \mathrm{O}_{8} & \text { triuranium octaoxide } \\ \mathrm{UF}_{4} & \text { uranium tetrafluoride } \\ \mathrm{UF}_{6} & \text { uranium hexafluoride }\end{array}$





\begin{abstract}
From a safeguards perspective, being able to verify declared technical design information of nuclear facilities is an important aspect of every safeguards approach. In addition to visual observation it is relevant to know if nuclear material is present or has been present in piping and ducts not declared. The possibility of combining different measurement techniques into one tool will optimize the inspection effort and increase safeguards effectiveness.

This report describes experiments conducted with gamma-ray imaging systems as part of a technical collaborative effort established by Oak Ridge National Laboratory (ORNL), Lawrence Berkeley National Laboratory (LBNL), Lawrence Livermore National Laboratory (LLNL), the Joint Research Centre at Ispra, Italy (JRC-Ispra) and the Brazilian-Argentine Agency for Accounting and Control of Nuclear Materials (ABACC), in the framework of the technical cooperation agreements between the U.S. Department of Energy (DOE) and the

European Atomic Energy Commission (EURATOM) and between the DOE and ABACC. The collaboration project was established to investigate the use of a three dimensional (3D) laser imaging system combined with gamma-ray imaging systems for international safeguards applications.

Gamma-ray imaging has the potential to reduce manpower needs and cost for effectively locating and monitoring special nuclear material. In a previous study, ORNL, LLNL and JRC-Ispra demonstrated the capability of combining outputs from a commercially available 3D laser system and a Compton gamma-ray imager prototype. The purpose of this report was to investigate the performance of pinhole and coded aperture gamma-ray imaging systems. With the aid of JRC-Ispra, radiometric data will be combined with scans from a 3D design information verification system. Measurements were performed at ORNL Safeguards Laboratory using sources that model holdup in radiological facilities. They showed that for situations with moderate amounts of solid or dense uranium sources, the coded aperture was able to predict source location and geometry within $\sim 7 \%$ of actual values, while the pinhole gave a broad representation of source distributions.
\end{abstract}





\section{INTRODUCTION}

Effective confirmation of presence of nuclear and radioactive material in decommissioned and operational radiological facilities is an important aspect of nuclear safeguards that is actively being researched. A recurring issue, for example, is determining the amount of nuclear holdup material present in uranium enrichment plants. Enriching uranium requires vast amounts of small and intricate machinery, which makes the accurate determination of radioactive deposits throughout these facilities quite difficult. Currently, the standard routine for performing holdup measurements is to send field technicians with scintillator or solid-state gamma-ray detectors to look for the gamma signature given off by uranium isotopes. Several limitations are encountered with this practice: (1) uranium deposits are sometimes located behind heavy processing equipment, hindering physical access to the source of radiation; (2) an adequate survey of a radiation area requires considerable manpower and time; and (3) radiation detectors used for holdup measurements are omnidirectional in that they do not provide information related to the direction of incident radiation. To alleviate these obstacles, gamma-ray imaging technology is being investigated, as documented in this report.

\section{BACKGROUND}

\subsection{PRELIMINARY CONSIDERATIONS}

In addition to radiometric information, design verification is a vital element for safeguards. Nuclear facilities contain intricate and elaborate equipment (e.g., reprocessing equipment, complex piping systems), often making traditional design verification through comparison of engineering drawings a cumbersome and inaccurate exercise. To eliminate this difficulty, the European Commission Joint Research Centre (JRC) at Ispra, Italy, developed an infrared laser system capable of three-dimensional design information verification (3D-DIV). It produces images through phase shifts between incident and reflected lights with $310^{\circ}$ and $360^{\circ}$ fields of view in the vertical and horizontal planes, respectively. Computer algorithms are used to combine the two-dimensional (2D) images obtained from the scanner into a single three-dimensional (3D) mesh(Coates et al. 2007). Figure 1 shows a typical setup for the 3D-DIV system.

The notion of combining 3D-DIV maps with radiometric images arose out of a collaboration among JRC, Oak Ridge National Laboratory (ORNL), and Lawrence Livermore National Laboratory (LLNL). ORNL researchers had obtained a 3D-DIV system from JRC, which they then transported to LLNL for investigation of the possibility of back-projecting its 3D maps onto images obtained from a Compton-based imager developed there. A combined 3D-DIV and Compton image map is shown in Fig. 2. Radiometric data are displayed at the right side of the map. As expected, the combined image enables one to simultaneously examine radiometric and design information.

Building upon the work done at LLNL, ORNL investigated the performance of pinhole and coded-aperture gamma-ray imaging systems. With the aid of JRC, gamma-ray images and 3D-DIV maps will be combined in a similar fashion to the 3D and Compton-imager combination at LLNL. Image acquisition was carried out at the ORNL Safeguards Laboratory and uranium hexafluoride $\left(\mathrm{UF}_{6}\right)$ flow loop. 


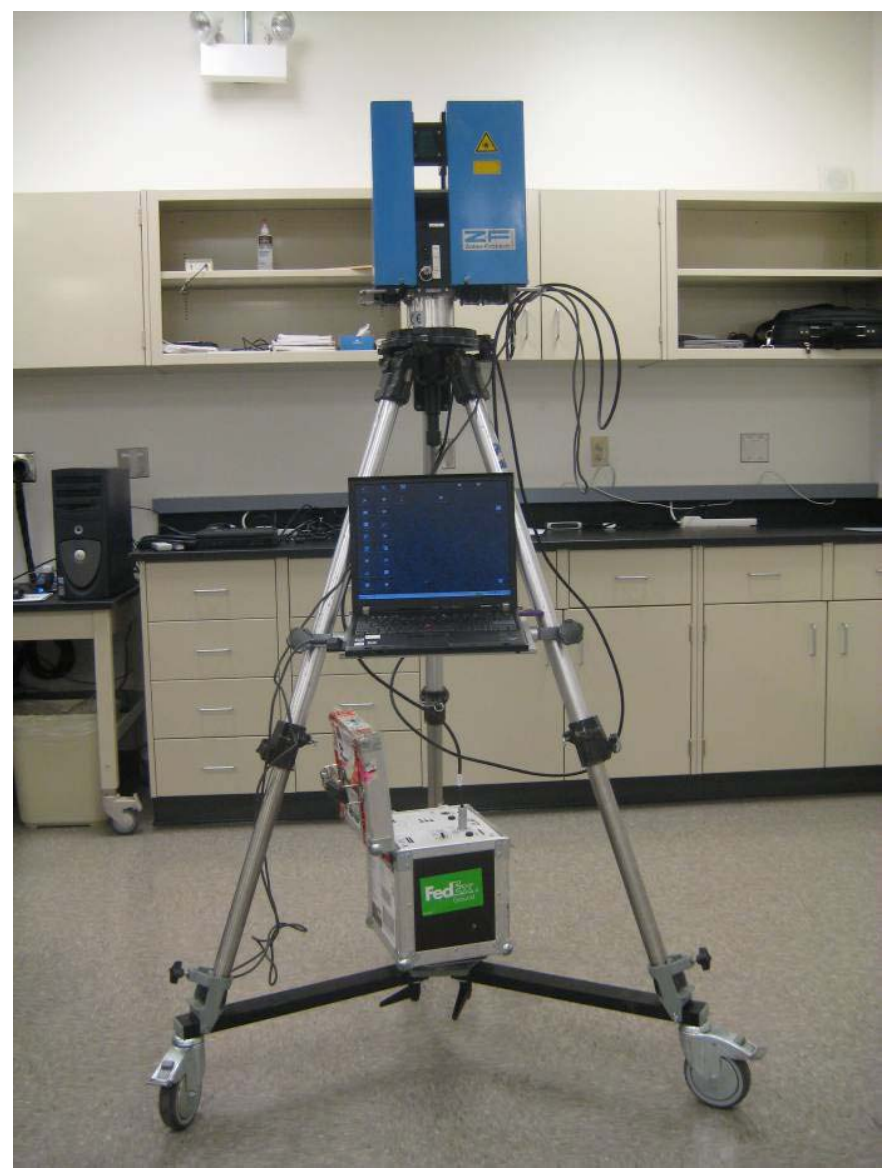

Fig. 1. Portable 3D-DIV system.

\subsection{GAMMA-RAY IMAGING TECHNIQUES}

\subsubsection{Compton Imaging}

Imaging using the Compton method eliminates the need for collimation, which means one can register more counts because no attenuation losses from shielding materials are encountered. The imaging mechanism requires incoming photons to Compton scatter* in the detection medium. As an example, after the Compton interaction the scattered photon can be completely absorbed (photoelectric interaction) in the surrounding medium, resulting in energy deposition at two distinct positions, as shown in Fig. 3. Based on this type of interaction sequence, conic imaging elements are obtained that are back-projected on 2D spherical, cylindrical, or planar surfaces. A statistically sound image created from Compton cones is produced only after a number of interaction sequences from the source are correctly projected onto the imaging surface (Mihailescu 2008).

\footnotetext{
* Compton scattering is an interaction event where a photon strikes a stationary free electron, with the end result being the electron set into motion and the photon scattered.
} 


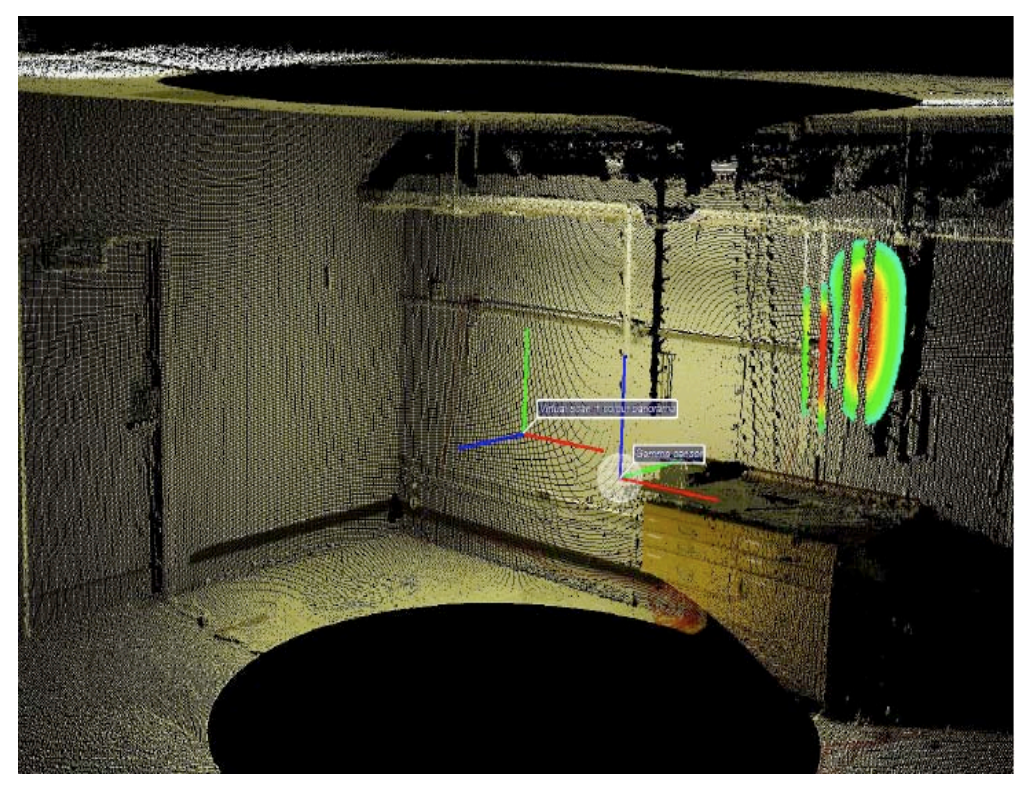

Fig. 2. Compton image back-projected onto a 3D-DIV map (Chivers 2008).

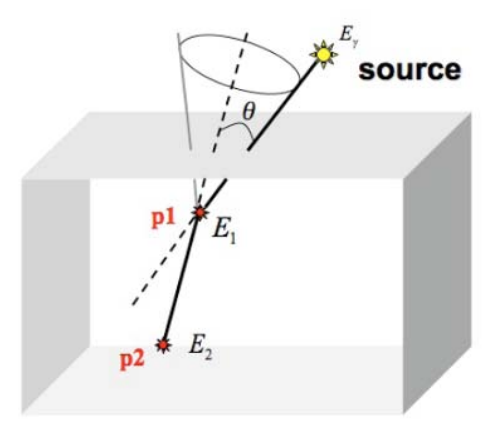

Fig. 3. A conic imaging element derived from an interaction sequence of two energy depositions $\left(E_{1}, E_{2}\right)$ at $\mathrm{p} 1$ and $\mathrm{p} 2$ from an incident gamma-ray source with energy $E_{\gamma}$ (Mihailescu 2008). Compton imaging was not investigated for this report.

\subsubsection{Pinhole Imaging}

Pinhole imaging is the simplest and least expensive technique used in gamma cameras. It involves placing a pinhole collimator between the detector and a source of interest (Fig. 4). Smaller pinhole (aperture) sizes produce sharper the images. However, the collimator material will attenuate most of the radiation emitted from the source. As a result, long count times are required to produce satisfactory radiometric images. 


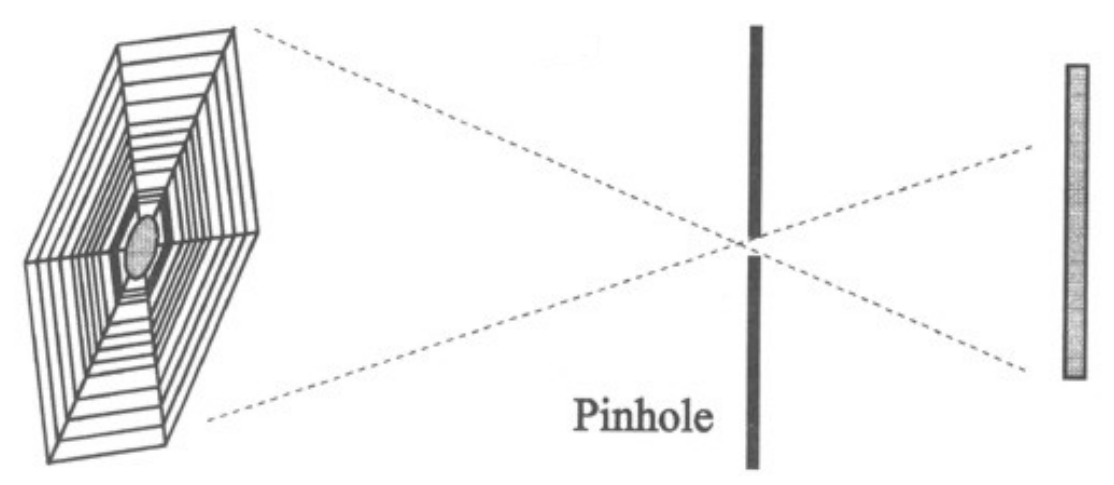

Fig. 4. Schematic showing the mechanism of pinhole imaging. Because no lens is used, the final image will be upside down relative to the imaged object (Gruntman 1997).

Pajarito Scientific Corporation supplied the pinhole-imaging device, RadScan ${ }^{\mathrm{TM}}$, used at ORNL. It consists of a sodium iodide scintillation detector positioned behind a tungsten collimator. The detector is not pixilated, which means that the instrument must raster scan an area of interest for image acquisition. Attached to the imaging head is a digital camera, which is used to overlay radiometric data with scanned area photographs. A typical setup is shown in Fig. 5. The imaging head can either hang freely or be mounted on a tripod, depending on the measurement conditions.

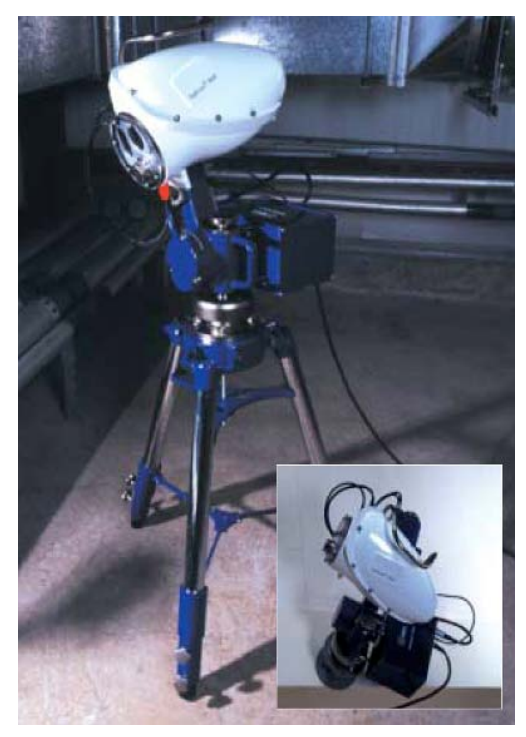

Fig. 5. RadScan ${ }^{\mathrm{TM}}$ imaging device (Pajarito Scientific Corporation). 


\subsubsection{Coded Aperture Imaging}

Coded apertures were first developed by replacing the opening of a simple pinhole camera with many holes that are arranged in a random pattern. Given a source field, individual source pixels cast unique shadow patterns onto the detector through a coded aperture mask (Fig. 6). These shadows can then be deconvoluted to give the desired image. Compared with pinhole instruments, coded apertures improve the signal-to-noise ratio by a factor of $\sim \sqrt{N}$, where $\mathrm{N}$ is the number of holes on the mask, because they allow more incident radiation to hit the detector. Nonetheless, unlike with pinhole cameras, there is always an uncertainty associated with the location of the emitted radiation due to artifacts produced by image deconvolution (Fenimore and Cannon 1978). As a result, coded apertures excel in imaging distributed sources, while pinhole technology is more appropriate for orphaned ones.

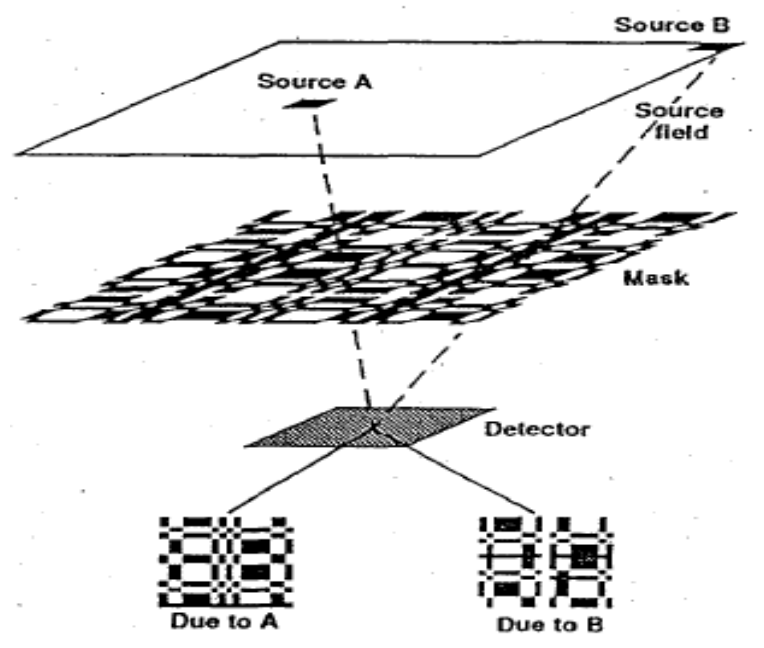

Fig. 6. Images produced with coded apertures arise out of source pixels from a source field casting unique shadows onto the detector (Ziock et al. 1992).

The coded aperture device used at ORNL is a prototype developed by K. Ziock, M. Burks, C. Cork, E. Hull, and N. Madden (Fig. 7). It employs a 38 by 38 cross-strip planar germanium detector $11 \mathrm{~mm}$ thick with a $2 \mathrm{~mm}$ pitch. A $5 \mathrm{~cm}$ thick, $8 \mathrm{~cm}$ diameter coaxial germanium detector is used to increase the detection efficiency for higher-energy gamma rays. The coded aperture is a $6.1 \mathrm{~mm}$ thick mask made of tantalum. 


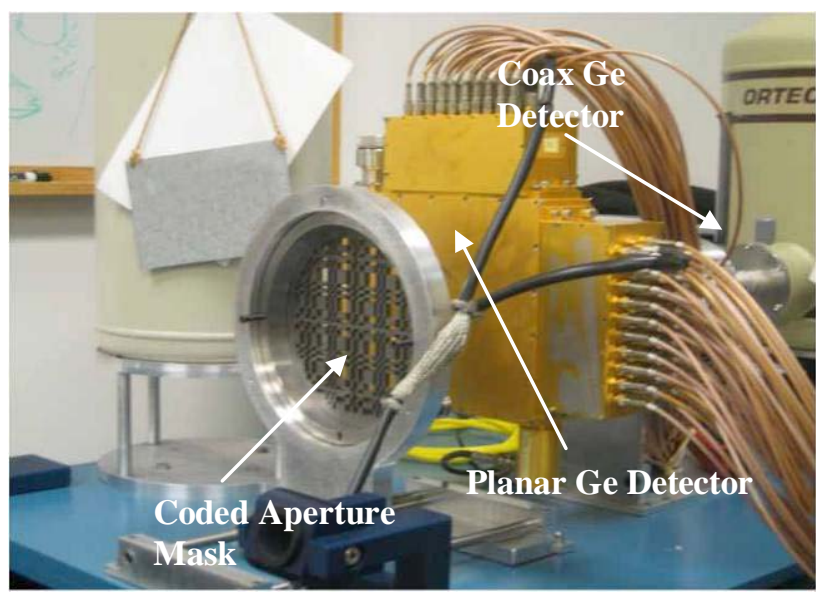

Fig. 7. Coded aperture imager. Both the planar and coax detectors are cooled by liquid nitrogen. The coax detector was not used for image acquisition.

\section{TEST PLAN}

A preliminary measurement was carried out to assess the quality of radiometric data given by the pinhole and coded aperture imagers. It involved setting up a mock pipe array $\sim 3.8 \mathrm{~m}$ from the imagers and initiating a $\sim 2.5 \mathrm{~h}$ count. Three uranium tetrafluoride $\left(\mathrm{UF}_{4}\right)$ vials (two of them containing $12.314 \mathrm{~g}$ of uranium and the other $11.372 \mathrm{~g}$ of uranium, all at $93 \%$ enrichment), were placed into hinges of the array. A distance of $55 \mathrm{~cm}$ separated the top and middle vials, while $41 \mathrm{~cm}$ of piping separated the middle and bottom vials. The top and bottom pipes, each, of the array contained a triuranium octaoxide $\left(\mathrm{U}_{3} \mathrm{O}_{8}\right) 90 \mathrm{~cm}$ line source with $4.8 \mathrm{~g}$ of uranium at $65 \%$ enrichment. Based on the radiometric images obtained from this measurement, one device will be chosen for further testing, which will include using different sources that model nuclear holdup such as ducts, filters, and flow loops.

\section{RESULTS AND DISCUSSION}

\subsection{PRELIMINARY TEST}

Results from the preliminary test are shown in Fig. 8. The coded aperture instrument provided a comprehensive radiometric image, as evinced by the clear presence of the $\mathrm{U}_{3} \mathrm{O}_{8}$ line sources. It also correctly identified the geometric distribution of the sources. With image pixels corresponding to $\sim 7 \mathrm{~cm}$ in the experimental geometry, the lengths of the line sources were computed to be $\sim 85 \mathrm{~cm}$. The distance between the top and center $U_{4}$ vials was calculated to be $\sim 49 \mathrm{~cm}$, while the distance between the center and bottom vials was $\sim 42 \mathrm{~cm}$. These computed values are within $\sim 6 \%$ of the known geometry. The RadScan ${ }^{\mathrm{TM}}$ detected $\mathrm{UF}_{4}$ vials at the pipe array hinges but gave a broad representation of the line sources. This result is attributed to its nonpixilated detector setup; with an $2.5 \mathrm{~h}$ integration, the RadScan ${ }^{\mathrm{TM}}$ has a dwell time of $2 \mathrm{~min}$ for each position on the pipe array. Thus, for distributed sources modeling nuclear holdup, using the coded aperture instrument may be preferable. 

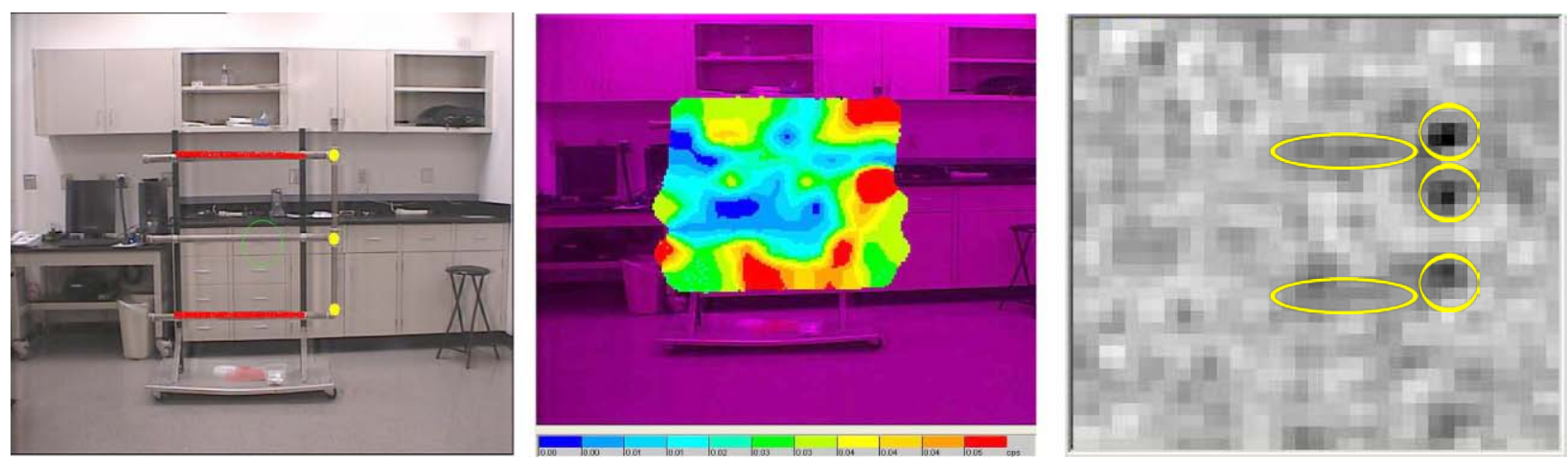

Fig. 8. Results from preliminary test. Left - Pipe array with three $\mathrm{UF}_{4}$ bulk sources (yellow) and two $\mathrm{U}_{3} \mathrm{O}_{8}$ line sources (red). Middle - RadScan image. Right - Coded aperture image (yellow lines added manually).

\subsection{FURTHER TESTS WITH CODED APERTURE IMAGER}

Further tests with the coded aperture instrument involved four measurements. The first three were done using different mock-up sources while maintaining the exact geometry of the pipe array measurement: $~ 3.8 \mathrm{~m}$ source-detector distance, $~ 7.5 \mathrm{~cm}$ mask-detector distance (focal length), and $\sim 7 \mathrm{~cm}$ pixel size. The last test involved measurements at the ORNL $\mathrm{UF}_{6}$ flow loop. Results for the first mock-up, a small round duct, are shown in Fig. 9. Inside the duct is a $177.5 \mathrm{~cm} \mathrm{U}_{3} \mathrm{O}_{8}$ line source at $65 \%$ enrichment containing $8.06 \mathrm{~g}$ uranium. The output image successfully portrayed the line source inside the duct. Furthermore, a hot spot (in dark black) was observed because two line sources overlapped at the far left end of the duct. The computed source length was $\sim 177 \mathrm{~cm}$, which is within $0.23 \%$ of the known value.
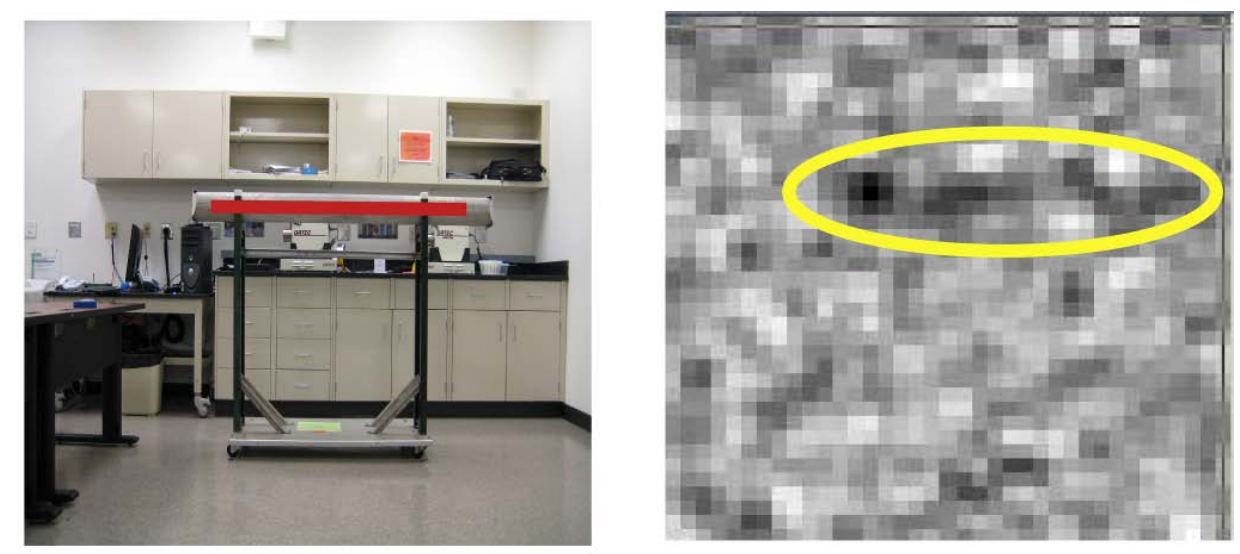

Fig. 9. Experimental setup and results from first mock-up. Left - Experimental setup for the small round duct. The red represents the $\mathrm{U}_{3} \mathrm{O}_{8}$ line source inside the duct. Right - Radiometric image from the coded aperture after $1 \mathrm{~h}$ count.

A high-efficiency particulate air (HEPA) filter was used to examine the detection limits of the coded-aperture imager. The first measurement simulated a case in which only trace amounts of 
enriched uranium are present in an area of interest. This was done using a 30 by $30 \mathrm{~cm}^{2}$ plane and four $17.81 \mathrm{~cm}^{2}$ disk $\mathrm{U}_{3} \mathrm{O}_{8}$ sources (93\% enriched) for a total uranium mass of $1.519 \mathrm{~g}$. Figure 10 shows the radiometric image after a $3 \mathrm{~h}$ count. From a spectroscopy standpoint, not much can be inferred from the image without prior knowledge of the source setup. Hence, longer count times are required for very-low-activity measurements.

The second measurement investigated the effects of source shielding on the quality of radiometric images. To accomplish this, all sources inside the filter were taken out, and three 30.48 by $60.96 \mathrm{~cm}^{2}$ $\mathrm{U}_{3} \mathrm{O}_{8}$ (93\% enriched) plane sources were stacked at its rear end, yielding a total uranium mass of $\sim 40$ g. Shielding material included $3.887 \mathrm{~mm}$ of stainless steel and $27.94 \mathrm{~cm}$ of a steel-wood matrix that constitutes the filter. The experiment's geometry remained the same as the first HEPA filter test. Figure 11 shows a radiometric image for a $1 \mathrm{~h}$ count in which a marked presence of a plane source can be seen. Computing the source area using pixel size gave 28 by $56 \mathrm{~cm}^{2}$, which is within $7 \%$ of the actual value.
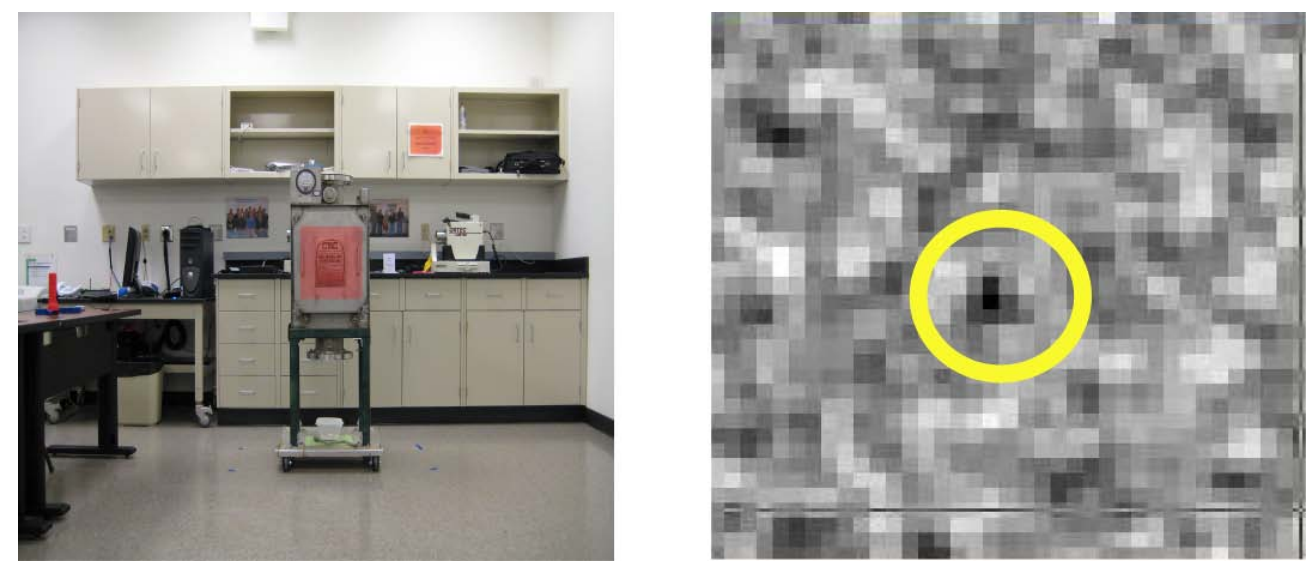

Fig. 10. HEPA filter test setup and radiometric image after $\mathbf{3} \mathbf{h}$ integration. Left - HEPA filter test setup. The transparent red rectangle represents the 30 by $30 \mathrm{~cm}^{2}$ planar $\mathrm{U}_{3} \mathrm{O}_{8}$ source. The disk sources are located at the top inside the filter. Right - Radiometric image given by the coded aperture instrument. The small dark spot highlighted by the yellow circle suggests the presence of a small plane source.

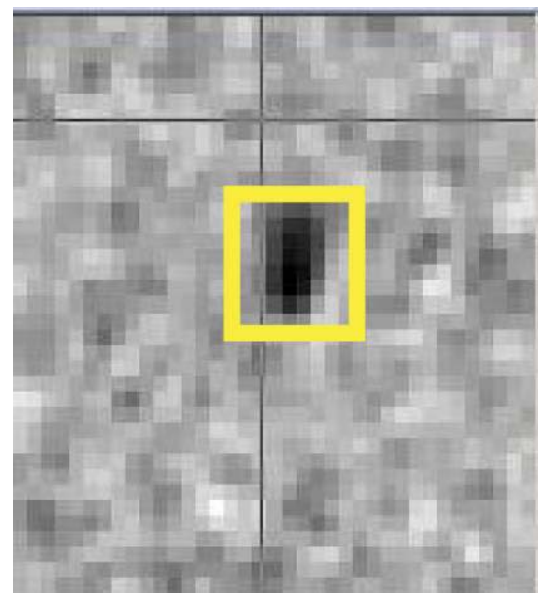

Fig. 11. Image obtained from a setup with three 30.48 by $60.96 \mathrm{~cm}^{2} \mathrm{U}_{3} \mathrm{O}_{8}$ card sources. 
Tests with a $\mathrm{UF}_{6}$ flow loop constituted the final phase of measurements for the coded-aperture imager. What makes the flow loop interesting for this experiment is that the source being imaged is significantly less dense than the laboratory sources used in other tests. In this case the source detector distance was $\sim 1.8 \mathrm{~m}$ with a $5.5 \mathrm{~cm}$ focal length, yielding a pixel size of $4 \mathrm{~cm}$. The Monel piping through which $90 \%$ enriched, $\sim 40$ torr $\mathrm{UF}_{6}$ gas flowed represented a total volume of $\sim 700 \mathrm{~cm}^{3}$. The gas was stored in a $667 \mathrm{~cm}^{3}$ aluminum tank measuring $\sim 34 \mathrm{~cm}$ wide. The image from a $16 \mathrm{~h}$ count is shown in Fig. 12. A marked presence of the $\mathrm{UF}_{6}$ in the aluminum tank can be seen; however, the gas in the Monel piping was not detected.
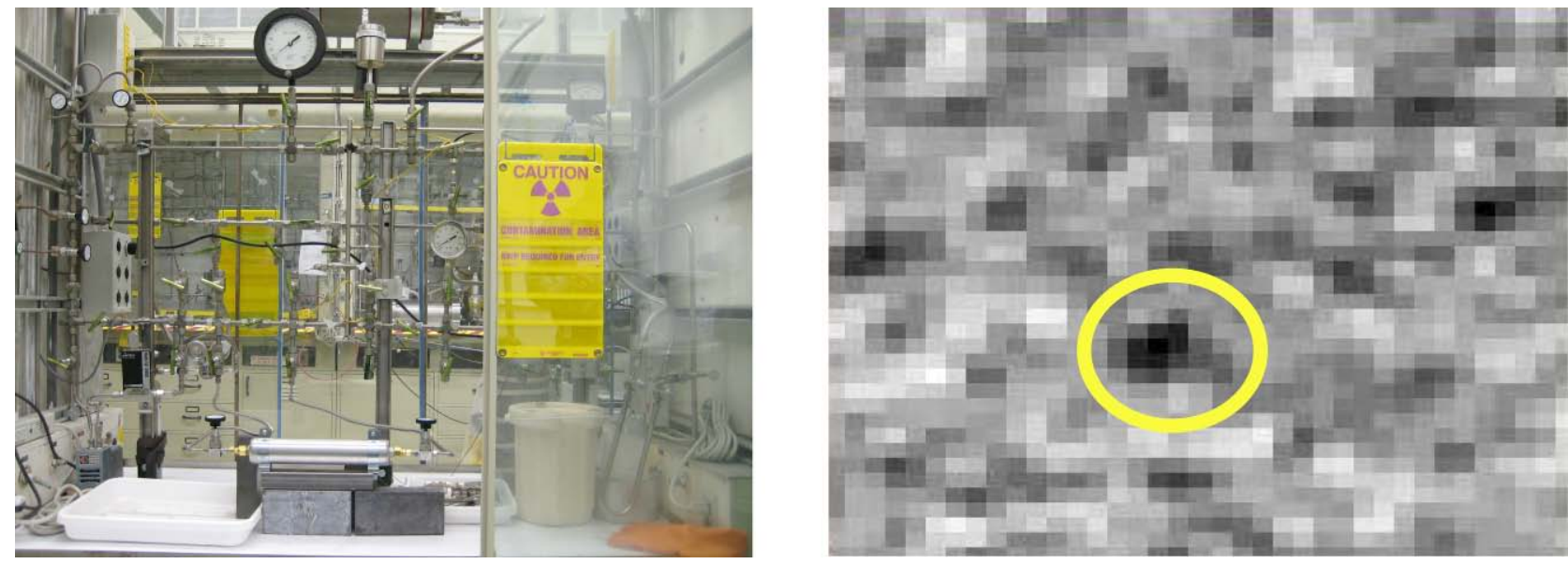

Fig. 12. Flow loop setup and radiometric image after $16 \mathrm{~h}$ count. Left - UF 6 flow loop setup. An aluminum tank sits beneath the Monel piping at the center position. Right - Radiometric image after a

16 h count.

\section{CONCLUSIONS}

For measurements involving distributed sources encountered in the safeguards field, the coded aperture imager might be more suitable than the pinhole instrument for imaging radiological sources and holdup. This was due to the pixilated nature of the radiation detector used by the coded aperture imager, which allowed it see an area of interest in one count. Further tests with the coded aperture imager showed that it is applicable in situations in which moderate amounts of solid (or dense) radiation sources are present. For these cases the imager can predict source location and geometry with a percent error less than $\sim 7 \%$. In situations with low activity/density sources, more direct detection methods are recommended over coded aperture imaging. In those situations pinhole imaging may be a better option because no imaging artifacts are encountered (although longer counts are needed). Indeed, a more accurate comparison between pinhole and coded aperture techniques can be carried out in the future by building a pinhole collimator for the cross-strip germanium detector currently used by the coded aperture device. 


\section{REFERENCES}

Chivers, D. 2008. "Pulse Shape Parameterization and Signal Decomposition for High Sensitivity Compton Imaging using High-Purity Germanium Double-Sided Strip Detectors.” Ph.D dissertation. University of California, Berkeley, California.

Coates, C.W., S.E. Smith, A. Hanson, J.B. Hines, A.C. Raffo Caiado, V. Sequeira, and J.G.M Gonclaves. 2007. Investigating Applications for the 3D Design Information Verification System at Department of Energy Facilities in the United States. ORNL/TM-2007/20. Oak Ridge National Laboratory, Oak Ridge, Tenn.

Fenimore, E.E., and T.M. Cannon. 1978. "Coded Aperture Imaging with Uniformly Redundant Arrays.” Applied Optics 17, No. 3,

Gruntman, M. 1997. "Energetic Neutral Atom Imaging of Space Plasmas.” Review of Scientific Instruments 68, No. 10, 3617-3656.

Mihailescu, L. 2008. “3D Gamma-Ray Imaging for Safeguards.” GNEP Safeguards Campaign Working Group Meeting,

Ziock, K.P., C.J. Hailey, T.B. Gosnell, and J.H. Lupton. 1992. “A Gamma-Ray Imager for Arms Control.” IEEE Trans. on Nuclear Science 39, No. 4, 